\title{
EARLY STAGES OF COPPER ELECTRODEPOSITION ON COLUMNAR STRUCTURED PLATINUM ELECTRODES
}

\author{
M. E. Martins, R. C. Salvarezza and A. J. Arvia \\ Instituto de Investigaciones Fisicoquimicas Teóricas y Aplicadas (INIFTA), \\ Universidad Nacional de La Plata, Casilla de Correo 16, Sucursal 4, (1900) La Plata, Argentina
}

(Received 30 January 1992)

\begin{abstract}
The electrodeposition of $\mathrm{Cu}$ from diluted $\mathrm{CuSO}_{4}$ in $0.5 \mathrm{M} \mathrm{H}_{2} \mathrm{SO}_{4}$ on columnar structured $\mathrm{Pt}$ electrodes was studied through voltammetry. For a constant set of experimental conditions, as the $\mathrm{Pt}$ electrode roughness is increased, bulk $\mathrm{Cu}$ electrodeposition tends to disappear, the amount of electroadsorbed $\mathrm{H}$ atoms increases, and the coverage of $\mathrm{Pt}$ by 2-D Cu domains decreases. This means that under non-equilibrium conditions for diluted $\mathrm{Cu}^{2+}$-ion-containing solutions and highly rough $\mathrm{Pt}$ substrates, 3-D $\mathrm{Cu}$ nuclei, and 2-D Cu and free Pt domains are simultaneously present at the initial stages of the process. In these cases, bulk $\mathrm{Cu}$ can be detected when the degree of $\mathrm{Pt}$ surface coverage by $\mathrm{Cu}$ atoms exceeds 0.5 .
\end{abstract}

Key words: electrocrystallization, metal electrodeposition, electrode roughness, growth models, columnar structured metal electrodes.

\section{INTRODUCTION}

There are a number of systems for which a complete 2-D monolayer of Me on a foreign substrate can be formed at potentials more positive than the reversible potential $\left(E_{\mathrm{r}}\right)$ of the corresponding $\mathrm{Me} / \mathrm{Me}^{+}$redox couple[1-4]. These monolayers, whose structures have been ascribed to a 2-D gas[5], seem to be completed before the nucleation and 3-D growth of bulk Me occurs at potentials $\left(E_{\mathrm{d}}\right)$ more negative than $E_{\mathrm{r}}[1-4]$. Accordingly, the growth model for the $\mathrm{Me}$ electrodeposits implies the successive growth of 2-D domains under quasi-equilibrium followed by the growth of the 3-D Me phase. In a number of electrochemical systems this situation can be approached when the electrodeposition of Me proceeds on welldefined smooth substrates at potentials close to $E_{r}$.

The early stages of $\mathrm{Cu}$ electrodeposition on a foreign metal substrate are particularly interesting for understanding the mechanism of electrocrystallization of metals, including the transition from 2-D submonolayers to bulk Me deposits. From the standpoint of electrochemical kinetics the most relevant works on the cathodic formation of monolayers and multilayers of metal atoms were carried out by using polycrystalline Pt surfaces[6], platinized $\mathrm{Pt}[7]$ and well-defined crystallographic faces $[5,8]$, although the latter, as recently shown from scanning tunnelling microscopy (STM), contain a relatively large number of defects[3]. A different situation arises when the electrodeposition of Me takes place on a rough conducting substrate far from equilibrium conditions as often occurs in applied electrochemistry. In this case the validity of the preceding model is far from proven. This fact encourages the investigation of both the influence of the surface roughness of the substrate and the electrodeposition conditions on the early stages of Me electrocrystallization.

Data on $\mathrm{Cu}[9]$ and $\mathrm{Ag}$ electodeposition[10] on polycrystalline $\mathrm{Pt}$ at potentials $\left(E_{\mathrm{d}}\right)$ more negative than $E_{\mathrm{r}}$ showed that the nucleation and 3-D metal overlayer growth involves a 2-D to 3-D rearrangement at growing sites. Hence, under those conditions the electrodeposited $\mathrm{Me}$ monolayer becomes unstable, and during a certain initial period of the electrodeposition process, free substrate and 2-D Me domains can coexist with 3-D Me nuclei.

Recently the influence of surface roughness on both underpotential (upd) and overpotential (opd) electrodeposition of $\mathrm{Ag}$ has been studied on columnar structured $\mathrm{Pt}$ electrodes[11]. The structure of these electrodes has been solved through the application of STM at the nanometre level[12,13] and their use is particularly attractive for detecting surface rearrangements and other dynamic aspects of the Me surface at the early stages of electrocrystallization. Usually these features cannot be observed on smooth conducting surfaces.

This work refers to the electrodeposition of $\mathrm{Cu}$ on columnar structured Pt electrodes comprising a rather wide range of roughness factors. The physical picture derived from the present results for the early stages of Me electrodeposition under relatively fast perturbing potential conditions is consistent with the simultaneous presence of bulk $\mathrm{Cu}, 2-\mathrm{D} \mathrm{Cu}$ domains and free $\mathrm{Pt}$ sites. This conclusion can be compared with previously reported data for Me electrodeposition at potentials close to $E_{\mathrm{r}}[9,10]$. Furthermore, when $E \ll E_{\mathrm{r}}$, the growth of bulk Cu deposits can occur when the surface coverage of the substrate by 2-D Cu domains exceeds 0.5 .

\section{EXPERIMENTAL}

The starting working electrode was a polycrystalline (pc) $\mathrm{Pt}$ wire $\left(99.99 \%\right.$ purity, $0.05 \mathrm{~cm}^{2}$ geometric area) encased in a glass holder. The electrochemical cell was completed with a Pt counter electrode $\left(4 \mathrm{~cm}^{2}\right.$ geometric area). A reversible hydrogen 


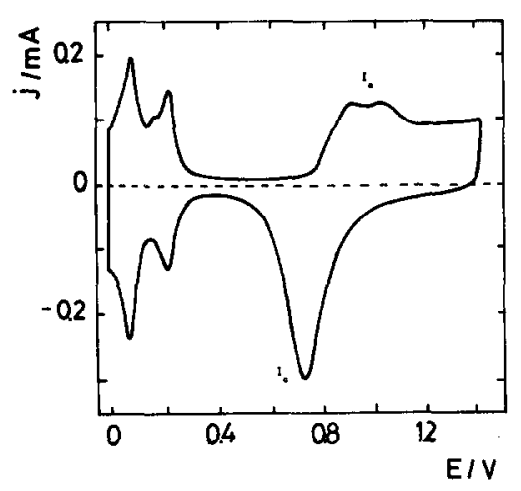

Fig. 1. Voltammogram of EDPtE in $0.5 \mathrm{M} \mathrm{H}_{2} \mathrm{SO}_{4}: v=0.1 \mathrm{~V}$ $\mathrm{s}^{-1} ; 25 \mathrm{C} ; R=30$. Apparent geometric area, $0.05 \mathrm{~cm}^{-2}$.

electrode ( $r h e$ ) in the same electrolyte solution was employed as reference electrode. The electrolyte solutions were $10^{-3} \mathrm{M} \mathrm{CuSO}_{4}+0.5 \mathrm{M} \mathrm{H}_{2} \mathrm{SO}_{4}$ and $0.5 \mathrm{M}$ $\mathrm{H}_{2} \mathrm{SO}_{4}$, the latter being employed for the blanks. Solutions were prepared from p.a. quality chemicals and Milli-Q* water. Runs were made at $25^{\circ} \mathrm{C}$ under $\mathrm{N}_{2}$ saturation at atmospheric pressure. The purity of the solution is extremely important for producing clean electrodispersed Pt electrode surfaces and for obtaining reproducible $\mathrm{Me}$ electrodeposits on it. The cleanness of the electrochemical system was systematically checked through the stability of the $\mathrm{H}$ adatom electrosorption cyclovoltammograms run in $0.5 \mathrm{M}$ $\mathrm{H}_{2} \mathrm{SO}_{4}$ at $0.1 \mathrm{~V} \mathrm{~s}^{-1}$ covering the $0.05-0.4 \mathrm{~V}$ range.

The columnar structured Pt electrodes [hereafter denoted as electrodispersed Pt electrodes (EDPtE)] were made in $1 \mathrm{M} \mathrm{H} \mathrm{H}_{2} \mathrm{SO}_{4}$ by using a technique described elsewhere[14]. The resulting EDPtEs exhibit roughness factors $(R)$ between about 2 and 200 .

The value of $R$ is defined as the $\left(Q_{\mathrm{H}}\right)_{R} /\left(Q_{\mathrm{H}}\right)_{\mathrm{i}}$ ratio, where $\left(Q_{\mathrm{H}}\right)_{\mathrm{R}}$ and $\left(Q_{\mathrm{H}}\right)_{\mathrm{i}}$ are the $\mathrm{H}$ atom electrodesorption voltammetric charge for the EDPtE, and that for the starting Pt electrode, respectively, both measured in $0.5 \mathrm{M} \mathrm{H}_{2} \mathrm{SO}_{4}$ under the same voltammetric conditions[15]. Similar values of $R$ were obtained by considering the $\mathbf{O}$ adatom electrodesorption charge resulting from single sweep voltammetry at $0.1 \mathrm{~V} \mathrm{~s}^{-1}$ between 1.45 and $0.5 \mathrm{~V}$. The values of $R$ were systematically checked both before and after each run.

The $\mathrm{Cu} / \mathrm{Cu}^{2+}$ electrode reactions in the upd and opd ranges on EDPtEs were studied through voltammetry from 0.05 to $1.45 \mathrm{~V}$ in the $0.02-0.1 \mathrm{~V} \mathrm{~s}^{-1}$ potential sweep $(v)$ range.

\section{RESULTS}

The voltammograms recorded for different EDPtEs in $0.5 \mathrm{M} \mathrm{H}_{2} \mathrm{SO}_{4}$ (Fig. 1) at $v=0.1 \mathrm{~V} \mathrm{~s}^{-1}$ exhibit the cathodic and the anodic O-electrosorption current peaks located at $0.75 \mathrm{~V}$ (peak Ic) and $0.7-1.4 \mathrm{~V}$ (peaks Ia), respectively. Besides, the current peaks related to $\mathrm{H}$ atom electrosorption are observed in the $0.05-0.35 \mathrm{~V}$ potential range. No marked voltammetric differences in $0.5 \mathrm{M} \mathrm{H}_{2} \mathrm{SO}_{4}$ can be detected for EDPtEs with $R$ ranging from 2 to 200.
The voltammograms obtained in $10^{-3} \mathrm{M} \mathrm{CuSO}_{4}+$ $0.5 \mathrm{M} \mathrm{H}_{2} \mathrm{SO}_{4}$ at $v=0.02 \mathrm{~V} \mathrm{~s}^{-1}$ (Fig. 2a-c) depend on the value of $R$. Thus, for $R=2$, the negative potential going scan shows peak I'c which involves the simultaneous contributions from the $O$ adatom monolayer electroreduction and the first stage of $\mathrm{Cu} u p d$, followed by a small and broad cathodic peak (IIc) located positively with respect to the reversible potential of the $\mathrm{Cu} / \mathrm{Cu}^{2+}$ electrode $\left(E_{\mathrm{r}}=0.250 \mathrm{~V}\right)$. Peak IIc is related to the second stage of $\mathrm{Cu}$ upd on $\mathrm{Pt}[9]$. At

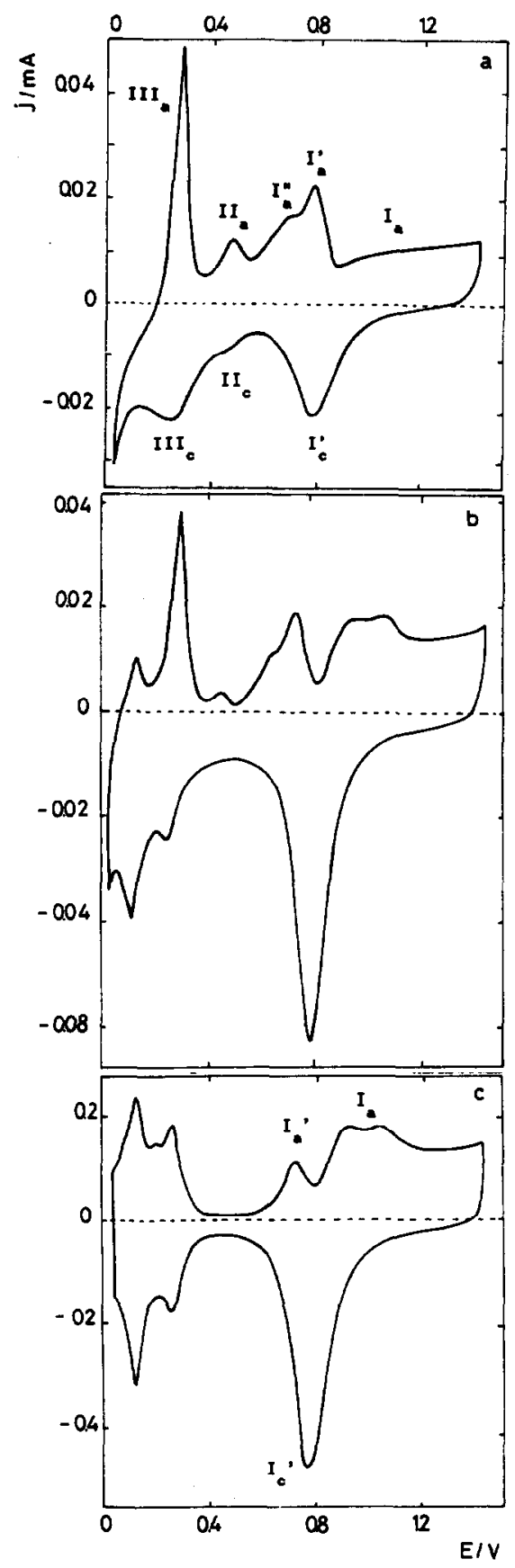

Fig. 2. Voltammograms for upd and opd $\mathrm{Cu}$ on different $\mathrm{Pt}$ electrodes. $10^{-3} \mathrm{M} \mathrm{CuSO}_{4}+0.5 \mathrm{M} \mathrm{H}_{2} \mathrm{SO}_{4} ; v=0.02 \mathrm{~V} \mathrm{~s}^{-1}$; 25C. (a) $R=2$; (b) $R=30$; (c) $R=180$. Apparent geometric area $0.05 \mathrm{~cm}^{2} .25 \mathrm{C}$. 


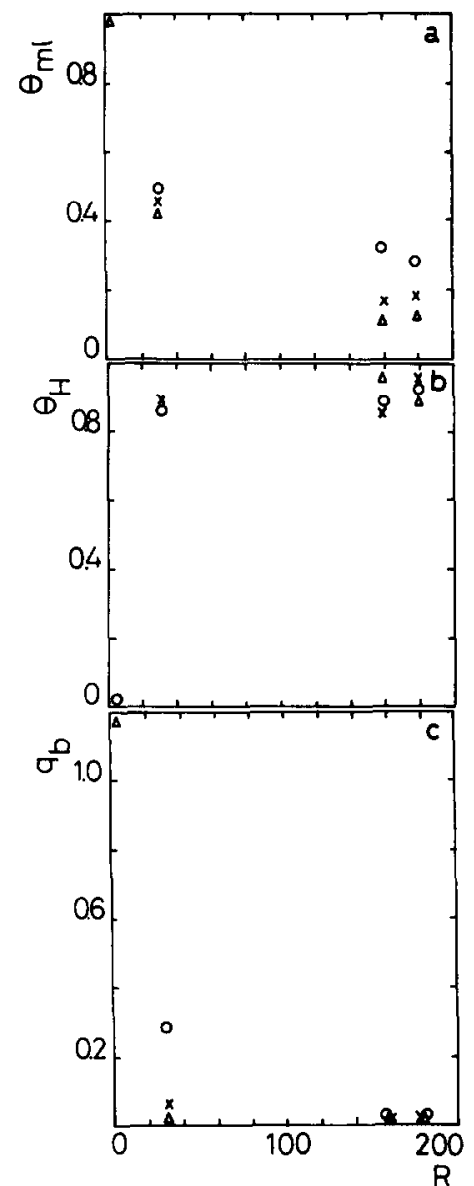

Fig. 3. Dependences of $\theta_{\mathrm{m} 1}$ on $R(\mathrm{a}) ; \theta_{\mathrm{H}}$ on $R(\mathrm{~b})$; and $q_{\mathrm{b}}$ on $R$ (c) derived from those voltammograms run at different $v s$ in $10^{-3} \mathrm{M} \mathrm{CuSO}_{4}+0.5 \mathrm{M} \mathrm{H}_{2} \mathrm{SO}_{4} ; 25 \mathrm{C}$. (O) $v=0.02 \mathrm{~V} \mathrm{~s}^{-1}$; $(\times) v=0.05 \mathrm{~V} \mathrm{~s}^{-1} ;(\triangle) v=0.10 \mathrm{~V} \mathrm{~s}^{-1}$.

potentials more negative than $E_{\mathrm{r}}$, a diffusion current peak (IIIc) related to bulk $\mathrm{Cu}$ electrodeposition (opd) is observed[9]. This peak partially overlaps the HER current which initiates at $c a 0.0 \mathrm{~V}$. Furthermore, the positive potential-going scan displays a large anodic peak (IIIa) due to the stripping of bulk Cu followed by three small current peaks IIa, I"a and I'a located at $0.45,0.62$ and $0.75 \mathrm{~V}$, respectively, all these peaks being related to the anodic stripping of upd $\mathrm{Cu}$. Similarly to the blank, at potentials more positive than $0.85 \mathrm{~V}$ the complex anodic peak Ia can be observed.

The metal electrodeposition/anodic stripping voltammograms run at $0.02 \mathrm{~V} \mathrm{~s}^{-1}$ (Fig. 2b and c) show that the increase of $R$ simultaneously produces a decrease in the charge density related to upd $\mathrm{Cu}$, an increase in the $\mathrm{H}$ atom electrosorption charge, and a considerable decrease in the anodic stripping charge related to opd $\mathrm{Cu}$. These results are largely comparable with those recently reported for upd and opd Ag on the same types of electrode[16].

Data derived from voltammetric runs in the $0.02 \mathrm{~V} \mathrm{~s}^{-1}<v<0.1 \mathrm{~V} \mathrm{~s}^{-1}$ range are summarized in Fig. 3a-c. In those plots $\theta_{\mathrm{H}}$ stands for the degree of surface coverage by $\mathrm{H}$ adatoms, $\theta_{\mathrm{ml}}$ is the degree of surface coverage by the upd metal, and $q_{\mathrm{b}}$ denotes the charge density of opd metal referred to the real rough Pt surface. For the evaluation of $\theta_{\mathrm{H}}$ and $\theta_{\mathrm{ml}}$ the corresponding monolayer charge density values were taken as 0.210 and $0.420 \mathrm{mC} \mathrm{cm}^{-2}$, respectively.

\section{DISCUSSION}

Data depicted in Fig. 3 indicate that under nonequilibrium conditions such as $\mathrm{Cu}$ electrodeposition on rough $\mathrm{Pt}$ surfaces $(R>30)$ the formation of 3-D $\mathrm{Cu}$ deposits decreases as $R$ and $v$ are increased. Thus, for $v>0.02 \mathrm{~V} \mathrm{~s}^{-1}$, the charge related to $3-\mathrm{D} \mathrm{Cu}$ deposits is beyond the possibilities of its electrochemical detection. The decrease of $q_{\mathrm{b}}$ is accompanied by the simultaneous changes in $\theta_{\mathrm{ml}}$ and $\theta_{\mathrm{H}}$, the latter becoming independent of $v[16]$. Furthermore, the decrease of $\theta_{\mathrm{ml}}$ and the simultaneous increase of $\theta_{\mathrm{H}}$ with increasing $R$ indicate that under certain conditions three processes are competing for reacting sites at the $\mathrm{Pt}$ substrate, namely the growth of 2-D Cu domains, the growth of bulk $\mathrm{Cu}$, and the $\mathrm{H}$-atom electroadsorption.

For explaining the preceding results one has to first consider that the structure of EDPtEs $(30<R<200)$ involves pores of $3 \times 10^{-5}-2 \times 10^{-4} \mathrm{~cm}$ length and $10^{-6} \mathrm{~cm}$ average width $[12,13]$. For the sake of simplicity, let us consider an intermediate value of $R$ such as $R \simeq 50$, with an average length of pores equal to $5 \times 10^{-5} \mathrm{~cm}$. Then the average number of $\mathrm{Cu}^{2+}$ ions contained in the pore volume for the electrolyte solution used in the present experiments is close to 10 , in contrast to $10^{4} \mathrm{Pt}$ surface atoms constituting the wall of the pore. Furthermore, from the standpoint of electrochemical kinetics, both the relatively high exchange current density $\left(j_{0}\right)$ value for $\mathrm{Cu} / \mathrm{Cu}^{2+}$ reaction[17] and the time required for the relaxation of the Nernst diffusion layer for a columnar structure equal to $5 \times 10^{-5} \mathrm{~cm}$ height, which is of the order of $0.1 \mathrm{~s}[18,19]$, have to be considered.

Under the present circumstances the electrodeposition of $\mathrm{Cu}$ is diffusion controlled by $\mathrm{Cu}^{2+}$ ions moving from the bulk of the solution towards the tips of the columnar Pt structure, ie the active Pt electrode surface is mainly constrained to the "envelope" of the rough substrate. Accordingly, the simplest physical picture for the early stages of $\mathrm{Cu}$ electrodeposition would imply the formation of 2-D Cu domains at tip sites whose average area can be estimated as $3 \times 10^{-12} \mathrm{~cm}^{2}$. The formation of 2-D Cu domains is followed by the growth of 3-D Cu deposits over those domains. Consequently, the bare Pt sites at the wall of the pores would remain as possible sites for $\mathbf{H}$ atom electroadsorption when the applied potential is set accordingly. This first mechanistic approach can be described as a "frozen particle" model as surface displacements of the depositing particles are not allowed. A scheme of the early stages of Me electrodeposition on the rough substrate in the absence of Me atom surface diffusion is illustrated in Fig. 4a-d. Unfortunately this model, which has been used to interpret the upd of Mes on different smooth conducting electrodes, fails to explain the initial stages of $\mathrm{Cu}$ electrodeposition on the EDPtEs, as the "frozen particle" model predicts a smooth decrease of $q_{b}$ with 

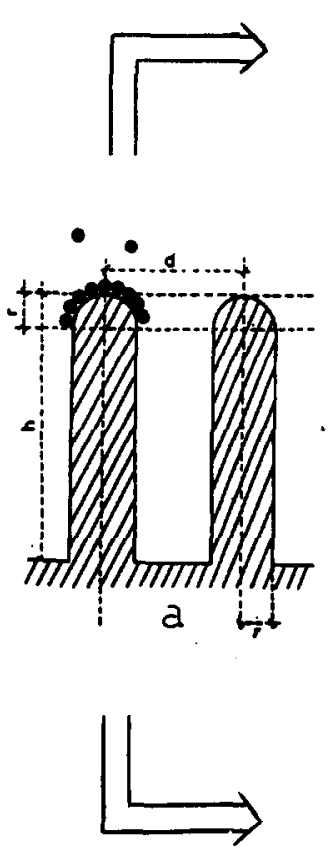
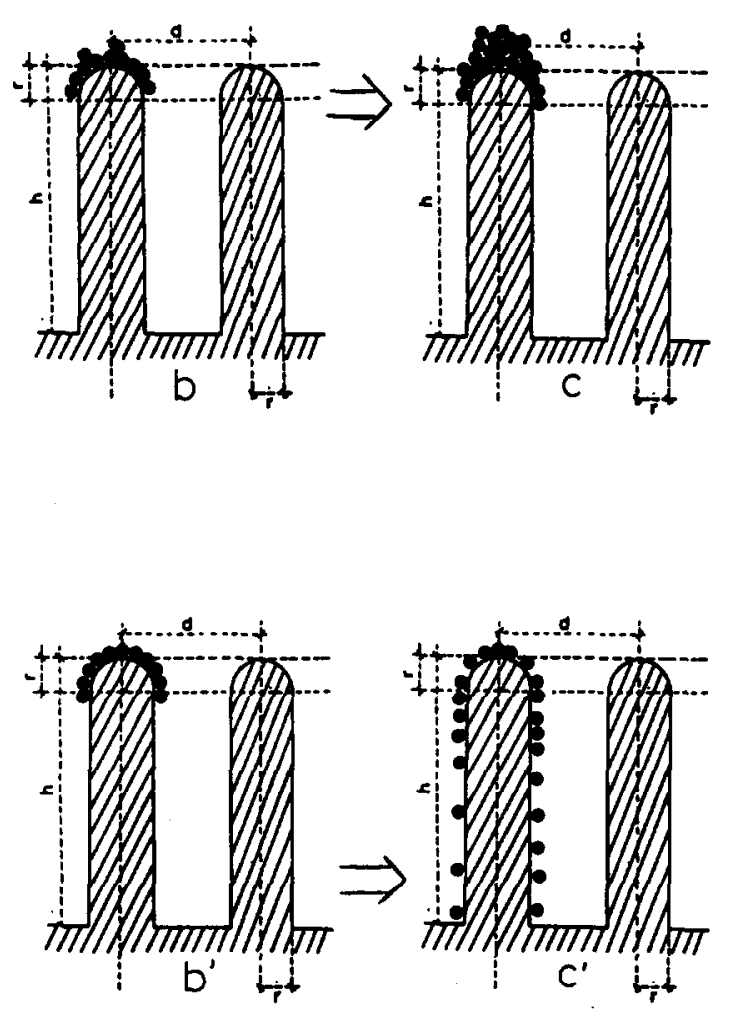
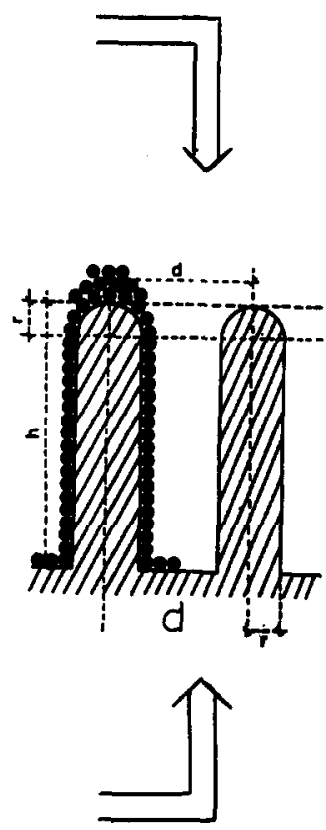

Fig. 4. Schemes for the early stages of a growing deposit $(O)$ on a columnar structured substrate. $h$, column height; $d$, intercolumnar distance; $r$, columnar radius. $[(a)+(b)+(c)+(d)]$, "frozen particles model"; $\left[(a)+\left(b^{\prime}\right)+\left(c^{\prime}\right)+(d)\right]$, "dynamic particles model". For the $\mathrm{Cu}-\mathrm{Pt}$ system the penetration of $\mathrm{Cu}$ atoms into bulk $\mathbf{P t}$ has not been considered as in this case there is no conclusive evidence of metal atoms inter/intradiffusion at room temperature.

increasing values of $R$. This means that some traces of $q_{b}$ would have to be detected even for those electrodes with the highest values of $R$ rather than the apparent complete inhibition of 3-D $\mathrm{Cu}$ growth actually observed within the possibilities of the voltammetric technique.

The explanation of the kinetics of the initial $\mathrm{Cu}$ electrodeposition on EDPtEs can be improved by considering that the arriving $\mathrm{Cu}$ atoms can diffuse on 2-D $\mathrm{Cu}$ domains formed at tip sites reaching free $\mathrm{Pt}$ sites at the wall of the pores. This approach implies that the surface mobility of $\mathrm{Cu}$ atoms at 2-D $\mathrm{Cu}$ domains is greater than their mobility on the $\mathrm{Pt}$ substrate. This assumption is consistent with the fact that the $\mathrm{Cu}-\mathrm{Cu}$ bonding energy appears to be weaker than the $\mathrm{Cu}-\mathrm{Pt}$ bonding energy, as deduced from the electrochemical data, ie from the potential values of the $\mathrm{Cu} u p d$ and $\mathrm{Cu}$ opd anodic stripping peaks. The high mobility of $\mathrm{Cu}$ surface atoms in contact with the electrolyte solution at room temperature is further supported by the STM imaging of the initial stages of $\mathrm{Cu}$ electrodeposition[5]. Correspondingly, the mobility of $\mathrm{Cu}$ surface atoms on 2-D Cu domains tends to produce a spillover effect which hinders the 3-D $\mathrm{Cu}$ growth (Fig. 5). A scheme of this reaction pathway is depicted in Fig. $4 a, b^{\prime}, c^{\prime}, d$. It should be noted that this type of surface atom rearrangement involving the relaxing and the reconstruction of metal deposits has been extensively studied on well-defined surfaces under either ultra- high-vacuum conditions or in contact with a gas phase[20].

On the other hand, for experimental conditions far from equilibrium there is a threshold value of $\theta_{\mathrm{ml}}$ for the formation of 3-D $\mathrm{Cu}$ deposits. This critical value of $\theta_{\mathrm{ml}}$ is about 0.5 , a figure which coincides with the

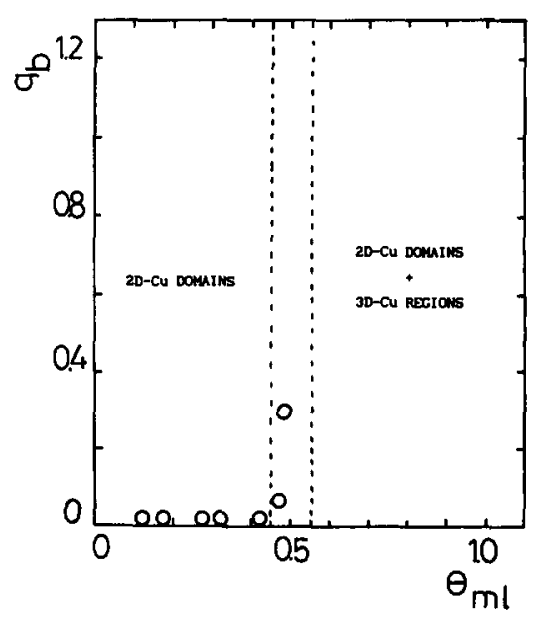

Fig. 5. $q_{\mathrm{b}}$ vs $\theta_{\mathrm{ml}}$ plot for $E \ll E_{\mathrm{r}}$. The 2-D Cu domains and the 2-D Cu domains + 3-D Cu growth regions are indicated. The probable transition range between those regions has been estimated around $\theta_{\mathrm{ml}}=0.5 \pm 0.05$. 
degree of Pt surface coverage by strongly bound $\mathrm{Cu}$ adatoms on $\mathrm{Pt}[9]$. This means that for $E_{\mathrm{d}} \ll E_{\mathrm{r}}$ the appearance of the 3-D $\mathrm{Cu}$ phase takes place when a fraction of the 2-D Cu monolayer involving strongly bound $\mathrm{Cu}$ adatoms has been formed.

\section{CONCLUSIONS}

(1) The voltammetric electrodeposition of $\mathrm{Cu}$ at different $v$ values on columnar structured $\mathrm{Pt}$ electrodes shows that at relatively high $v \mathrm{~s}$, as the roughness of the electrode is increased, the presence of bulk $\mathrm{Cu}$ electrodeposit tends to disappear, the amount of electroadsorbed $\mathrm{H}$ atoms increases, and the coverage of $\mathrm{Pt}$ substrates by 2-D $\mathrm{Cu}$ domains decreases.

(2) For fast $\mathrm{Cu}$ electrodeposition $\left(E \ll E_{\mathrm{r}}\right)$ from a diluted $\mathrm{Cu}^{2+}$ ion containing solution on EDPtEs involving a large roughness factor, there is an initial stage of the process in which 3-D Cu nuclei, 2-D Cu and free $\mathrm{Pt}$ domains are simultaneously present in the system.

(3) The early stages of $\mathrm{Cu}$ electrodeposition on EDPtEs reveal that both $\mathrm{Cu}$ atom surface diffusion and $2-D \Leftrightarrow 3-D$ reversible changes at the growing $\mathrm{Cu}$ layer play an important role in the overall process.

(4) At high $\mathrm{Cu}^{2+}$ ion discharge rates bulk $\mathrm{Cu}$ can be detected when the EDPtE surface coverage by 2-D $\mathrm{Cu}$ domains exceeds 0.5. This figure represents the maximum $\mathrm{Pt}$ surface coverage by strongly bound $\mathrm{Cu}$ adatoms on $\mathrm{Pt}$.

Acknowledgements-The authors thank the Consejo Nacional de Investigaciones Cientificas y Técnicas of Argentina, and the Comisión de Investigaciones Científicas de la Pcia. de Bs. As. for financial support.

\section{REFERENCES}

1. D. M. Kolb, in Advances in Electrochemistry and Electrochemical Engineering, Vol. 11 (Edited by $\mathrm{H}$. Gerischer and C. Tobias), Wiley, New York (1978).

2. H. Bort, K. Jüttner, W. J. Lorenz and E. Schmidt, J. electroanal. Chem. 90, 413 (1978).

3. L. M. Gassa, U. Schmidt, W. Obretenov, W. J. Lorenz, G. Staikov and E. Budevski, Electrochim. Acta 37, 2173 (1992).

4. F. El-Omar, R. Durand and R. Faure, J. electroanal. Chem. 160, 385 (1984).

5. O. M. Magnussena, J. Hotlos, R. J. Nichols, D. M. Kolb and R. J. Behm, Phys. Rev. Lett., 64, 2929 (1990).

6. M. Breiter, J. electrochem. Soc. 114, 1125 (1967).

7. M. Breiter, Electrochim. Acta 34, 1119 (1989).

8. D. M. Kolb, R. Kötz and K. Yamamoto, Surf. Sci. 87, 20 (1979).

9. D. Margheritis, R. C. Salvarezza, M. C. Giordano and A. J. Arvia, J. electroanal. Chem. 229, 327 (1987).

10. D. Alonzo and B. Scharifker, J. electroanal. Chem. 274, 167 (1989).

11. M. E. Martins, R. C. Salvarezza and A. J. Arvia, Electrochim. Acta 36, 1617 (1991).

12. L. Vázquez, A. Bartolomé, A. M. Baró, C. Alonso, R. C. Salvarezza and A. J. Arvia, Surf. Sci. 215, 171 (1989).

13. C. Alonso, R. C. Salvarezza, J. M. Vara, A. J. Arvia, L. Vázquez, A. Bartolomé and A. M. Baró, J. electrochem. Soc. 137, 2161 (1990).

14. A. Chialvo, W. E. Triaca and A. J. Arvia, J. electroanal. Chem. 171, 303 (1984).

15. S. Trasatti and O. A. Petrii, J. pure appl. Chem. 67, 711 (1991).

16. M. E. Martins, R. C. Salvarezza, J. M. Vara and A. J. Arvia, J. electrochem. Soc. 138, 2509 (1991).

17. J. O'M. Bockris and G. Razumney, Fundamental Aspects of Electrocrystallization. Plenum Press, New York (1967)

18. T. Pajkossy, J. electroanal. Chem. 30, 1 (1991).

19. P. Ocón, P. Herrasti, L. Vázquez, R. C. Salvarezza, J. M. Vara and A. J. Arvia, J. electroanal. Chem., in press.

20. F. Iona and P. Marcus, in The Structure of Surfaces II, p. 90, Springer, Berlin (1988). 